\title{
A Parametric Study on the Production of Bio Fuels from Rapeseed Oil
}

\author{
M. Shahbaz, M. A. Rasheed, M. S. Tahir, M. A. Ahmed, and Adeel Ikram
}

\begin{abstract}
Various research groups are on the way to develop cutting edge techniques for the production of environmental friendly fuels based on new green energy sources [1]. Bio-fuels have potential to reduce the emission of carbon dioxide $\left(\mathrm{CO}_{2}\right)$ and can help to overcome the global warming issue. Agricultural wastes and edible- oils are potential raw material for the production of energy and biodiesel. Extensive work has been reported on the characterization of agro-wastes and rapeseed oils for the production of fuel palettes and synthetic bio-diesel respectively. The cellulosic materials are generally been used for the production of bio ethanol. The present paper reports the effect of key reaction parameters such as Ethanol/oil ratio, reaction time, catalyst concentration, temperature, type of alkaline catalyst on the yield of the bio-diesel from rape seed oil and ethanol at different operating conditions. The results indicate that ethanol/oil ratio is the most significant reaction parameters on yield. Increase in concentration of ethanol/oil ratio enhances the bio diesel production whereas enhanced catalyst $(\mathrm{KOH}, \mathrm{NaOH})$ concentration has negative impact on the yield of bio-diesel.
\end{abstract}

Index Terms-Renewable energy, bio-diesel, ethanol, rapeseed oil, reaction conditions, catalysts.

\section{INTRODUCTION}

Now-a-days fossil fuels are not the sustainable sources of energy to meet the growing energy demand of the world due to rapid depletion of their reserves. Combustion of fossil fuel has negative impact on environment. [1] The emission of greenhouse gases from fossil fuel are responsible for major irregular climatic changes which has posed grave threat to cities lying just above the sea level [2]. Pakistan is an agriculture country enrich with biomass which is considered an abundant source of green energy. Biomass is the most sustainable and largest resource of energy in the world. According to some studies, the biomass available in the world is about 220 billion ton (oven dry) per annum [3].

The bio-diesel production as a renewable source is an effort towards the green energy source. Therefore this work focuses on proper utilization of the biomass for energy generation. Brazil is producing bio ethanol from sugarcane and Zimbabwe conducted a research on crop residue for energy generation. The research revealed that Zimbabwean crop residue has an energy potential to meet country's $44 \%$

Manuscript received May 6, 2013; revised July 2, 2013.

Muhamamd Shahbaz, Muhamamd Suleman Tahir, Muhamamd Ajaz Ahamd, and Adeel Akram are with Faculty of Engineering, University of Gujrat, Gujrat, Pakistan. (e-mail: Muhammad_shahbaz@uog.edu.pk, drsuleman.tahir@uog.edu.pk, adeel.ikram@uog.edu.pk).

Muhammad Asif Rasheed is with the royal institute of technology Stockholm Sweden (e-mail: tanoli_asif@hotmail.com). gross energy demand [4]. Growcom is a Queensland based horticultural services company who used banana feed stock firstly for biogas generation [5]. Yan et al., in 2010 calculated banana feed stock potential for power generation in Malaysia [6].

Fatty acid methyl esters (FAME) show large potential applications as diesel substitutes, and they are known as biodiesel. Unlike the conventional fossil fuel, diesel is produced after distillation of crude oil. Biodiesel is not only different in analytical characteristics such as its chemical formula, heating value, colour, odours, specific gravity, density but also due to its production categorized as renewable fuel.

Feedstock selection along with catalyst, alcohol, reaction temperature and time etc. are the deciding factors which are studied in this experimental setup.[7] Ethanol is selected as one of reactants in this laboratory setup is due to its ease of extraction from vegetation by anaerobic reactions of yeast and bacteria. The method is known for centuries and commonly employed in beverages and wines production. This would involve agricultural work force and utilize agro-resources and methodologies into industrial scale renewable fuel generation.

This method of biodiesel production is technically viable and enhanced harvesting of rapeseed plant is required for continuous production of renewable fuel (biodiesel) in order to enhance agricultural economy [8].

This experimental work is conducted for studying production of biodiesel under different experimental conditions. Alkaline homogeneous catalysis is employed which is convenient on industrial scale. During these reactions for bio- diesel production neutralization and separation steps are incorporated which require water, solvents and energy.

\section{MATERIAL AND METHODS}

In this study, conical flask is washed with acetone to remove any moisture and dried in oven at a temperature of $120{ }^{\circ} \mathrm{C}$. The required temperature for different experimental setups is maintained by digital boiling water baths. The stirring is achieved by magnetic stirrer. Bio diesel obtained is separated by separating funnel and washed with $5 \mathrm{wt} \%$ of phosphoric acid to remove alkalinity.

Amount of rapeseed oil is fixed and taken $200 \mathrm{ml}$ for each experiment with parameters to be varied are

- Reaction time ( 1 or 2 hours)

- Catalyst weight (0.8/1.5 grams for $\mathrm{NaOH}, 1.2 / 2.4$ grams for $\mathrm{KOH})$

- Temperature $\left(40 / 50{ }^{\circ} \mathrm{C}\right)$ 
- Volume of ethanol (60/90/125 ml)

- Type of catalyst $(\mathrm{NaOH} / \mathrm{KOH})$

Density of biodiesel for each experiment is measured by simple gravimetric method. For measuring density, the $25 \mathrm{ml}$ specific gravity bottle is filled and weighed it on electronic balance before and after filling the bottle. Using equation (1), the density of bio diesel is measured.

$$
\rho=\frac{m_{\text {biodiesel }}}{V_{\text {biodiesel }}}
$$

For the calculation of viscosity, the ball time flow viscometer is used. The viscometer is filled with each sample and subsequently recorded the time of flow of ball between two measured points. Using the equation (2) the viscosity is calculated.

$$
\eta=k \times t \times\left(\rho_{\text {reference }}-\rho_{\text {biodiesel }}\right)
$$

where,

$$
\begin{aligned}
& \eta=\text { viscosity of bio diesel } \quad\left(\mathrm{g} / \mathrm{cm}^{2}\right) \\
& K=\text { the geometric constant of ball }\left(\mathrm{cm}^{2}\right) \\
& t=\text { ball flow time } \quad(\mathrm{sec}) \\
& \rho_{\text {reference }}=\text { ball density } \quad\left(\mathrm{gm} / \mathrm{cm}^{3}\right) \\
& \rho_{\text {biodiesel }}=\text { bio diesel density } \quad\left(\mathrm{gm} / \mathrm{cm}^{3}\right)
\end{aligned}
$$

Viscosity of fuel is very important factor because it is directly related to engine performance. The desire viscosity increases the engine life otherwise high viscosity becomes the hindrance for smooth running of fuel filter.

Refractive index is measured by using Zeizz refracto meter. Refractive index is a cardinal property since it helps to measure the purity of fuel which confirms experimental success and fuel performance. It also helps to calculate the bio-diesel concentration. Standard value of RI of bio-diesel is 1.4576 .

\section{RESULTS AND DISCUSSION}

The results of this investigation are shown graphically here. It is evident from Fig. 1 that for same catalyst type ( the temperature at $40{ }^{\circ} \mathrm{C}$ and time at $1 \mathrm{hr}$ ) the increase in catalyst concentration enhances the yield, one reading of sample no3 has deviation from general trend because its yield increased from others but .Sample No 6 has decreased yield, which can be justified as this sample was ruined due to increased shaking after adding H3PO4.Moreover it was observed that with decreasing EtOH to Oil ratio consequently decreases yield keeping all the other parameters constant. And one reading deviate due to water and error in sampling of experiment.

It is clear from Fig. 2 when $\mathrm{KOH}$ used as a catalyst by decreasing EtOH to oil ratio the yield of bio diesel also decreased. It also shows that yield increased by increasing catalyst concentration.

As shown by Fig. 3.The yield is increased by increasing the Ethanol/Oil ratio keeping temperature constant. The yield is increased at $500 \mathrm{C}$ due to high temperature. In case of $\mathrm{KOH}$ catalyst the yield is increased with decreased the ETOH/Oil ratio in both cases of 50 and $400 \mathrm{C}$. The yield has increased by increasing temperature as shown in Fig. 4.

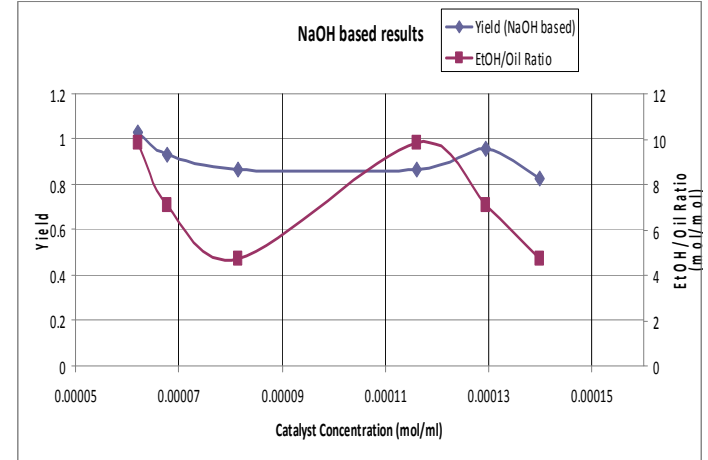

Fig. 1. Effect of concentration of catalyst on the yield of bio-diesel from rapeseed oil and ethanol/oil ratio with $\mathrm{NaOH}$.

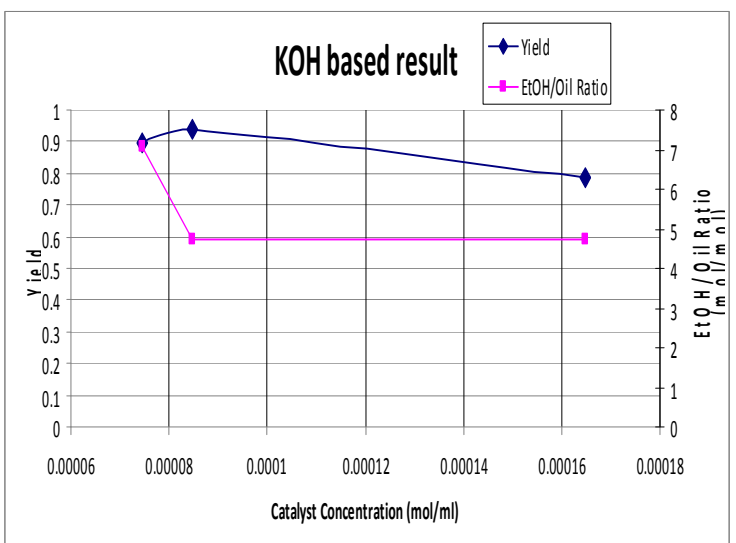

Fig. 2. Effect of concentration of catalyst on the yield of bio-diesel from Rapeseed oil and EtOH/oil ratio with $\mathrm{KOH}$.

Effect of Temperature $(\mathrm{NaOH})$

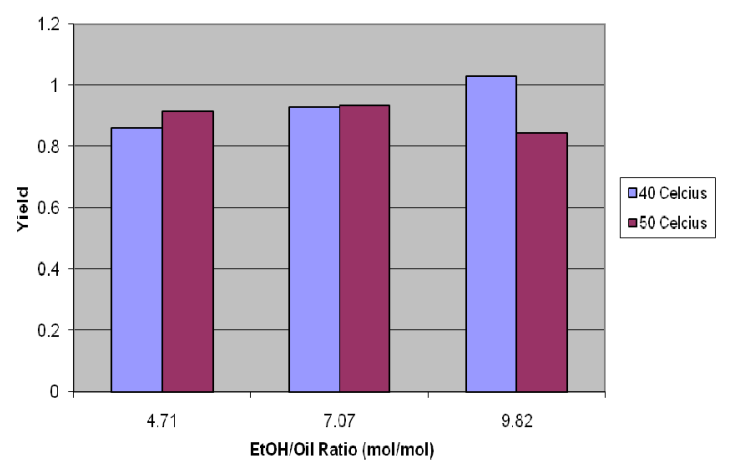

Fig. 3. Effect of temperature and Ethanol/oil ratio on yield of Biodiesel.

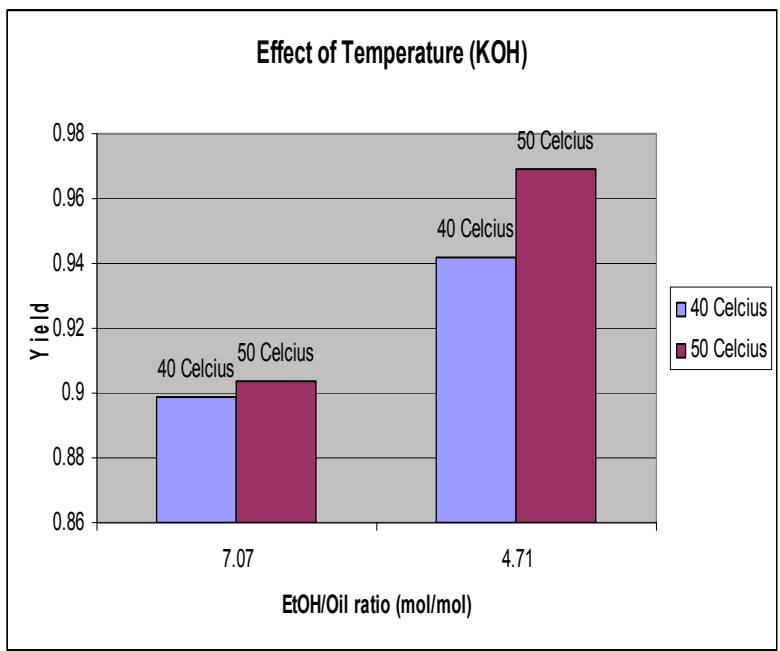

Fig. 4. Effect of Temperature and EtOH/oil ratio 


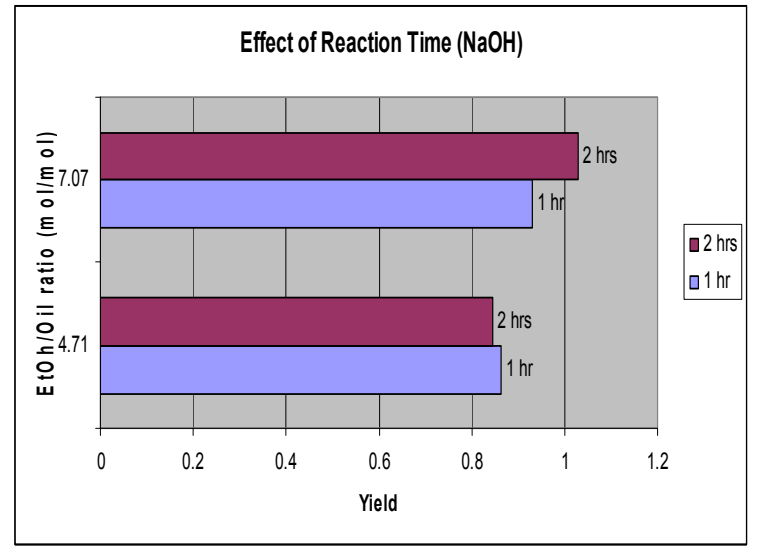

Fig. 5. Effect of reaction time and EtOH/oil ratio on yield of Biodiesel with $\mathrm{NaOH}$

As shown in Fig. 5, yield is high at low EtOH/Oil ratio for $1 \mathrm{hr}$ reaction time but it is not too high which can be explained as some human error or calculation mistake. On the other hand yield is too high for $2 \mathrm{hr}$ reaction time and it crossed the limit of 1 , which is not possible. On the whole normal tendency of higher yield at increased reaction time and increased EtOH to oil ratio can be observed.

So in case of $\mathrm{KOH}$ catalyst trend is obvious for $1 \mathrm{hr}$ reaction time that by increasing $\mathrm{EtOH} / \mathrm{Oil}$ ratio result in increased yield. For $2 \mathrm{hr}$ reaction time, the case is inverse with even lower yield at higher alcohol to oil ratio which is not a significant result as shown in Fig. 6.

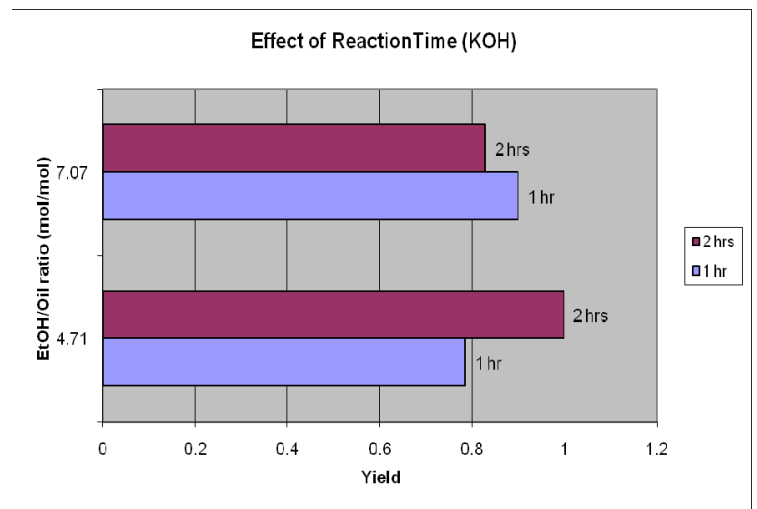

Fig. 6. Effect of reaction time and EtOH/oil ratio on yield of Biodiesel with $\mathrm{KOH}$

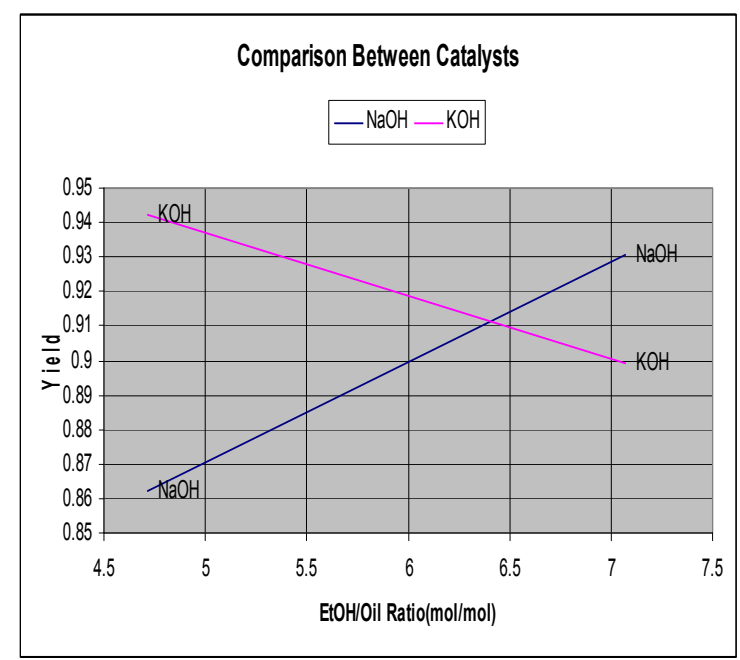

Fig. 7. Comparison of catalyst $(\mathrm{KOH}$ and $\mathrm{NaOH})$ and effect of EtOH/Oil ration on yield of Biodiesel
With same reaction time, temperature and same catalyst concentration, by varying the EtOH/oil ratio comparison between catalysts shows that by increasing EtOH/Oil ratio, yield is decreased for $\mathrm{KOH}$ while for $\mathrm{NaOH}$ yield is increased as shown in Fig. 7.

TABLE I: ETOH/OIL RATIO AND CONCENTRATION WITH TIME AND TEMPERATURE

\begin{tabular}{|l|l|l|l|l|l|}
\hline $\begin{array}{l}\text { Sample } \\
\text { No. }\end{array}$ & Catalyst & $\begin{array}{l}\text { EtOH/Oil } \\
\text { (Mole } \\
\text { ratio) }\end{array}$ & $\begin{array}{l}\text { Catalyst } \\
\text { concentration } \\
\text { (mol/ml) }\end{array}$ & $\begin{array}{l}\text { Time } \\
\text { (hrs) }\end{array}$ & $\begin{array}{l}\text { Temp } \\
\text { ('C) }\end{array}$ \\
\hline $\mathbf{8}$ & $\mathrm{KOH}$ & 4.71 & $8.24176 \mathrm{E}-05$ & 2 & 40 \\
\hline $\mathbf{9}$ & $\mathrm{KOH}$ & 4.71 & $8.46841 \mathrm{E}-05$ & 1 & 40 \\
\hline $\mathbf{1 3}$ & $\mathrm{KOH}$ & 4.71 & $8.24176 \mathrm{E}-05$ & 1 & 50 \\
\hline 18 & $\mathrm{NaOH}$ & 7.07 & 0.000208621 & 2 & 50 \\
\hline
\end{tabular}

\begin{tabular}{|l|l|l|}
\hline \multicolumn{2}{|c|}{ TABLE II: PROPERTIES OF BIO DIESEL } \\
\hline & Standard Values [1] & $\begin{array}{l}\text { Calculated Averaged } \\
\text { values }\end{array}$ \\
\hline Density (g/cm3) & $0.85-0.89$ & 0.865 \\
\hline $\begin{array}{l}\text { Dynamic viscosity } \\
\left(\mathrm{cPX} 10^{-3}\right)\end{array}$ & $1.67-5.28$ & 3.88 \\
\hline Refractive Index & 1.4576 & 1.452 \\
\hline
\end{tabular}

\section{CONCLUSION}

The results show that yield is mostly affected by ethanol to oil ratio. The increase in ethanol to oil ratio increases yield. One change is observed for the different types of catalysts. $\mathrm{KOH}$ has decreasing trend after a certain ethanol to oil ratio. Moreover, very strange effect of catalyst concentration with respect to yield is found. Increasing catalyst has negative effect on the yield. Therefore, it is better to use little amount of catalyst for getting optimal yield. For increasing reaction time, the yield increased which was shown in experiments except one deviation of potassium hydroxide case for 2 hours when the yield was decreased when ethanol to oil reaction is increased simultaneously with reaction time. As a whole sodium hydroxide has better results and ease in experiment than potassium hydroxide. One other observation was no glycerol for the sample no. 8, 9, 12, 13, 18 which can be summarized in Table I.

Which indicate that $\mathrm{KOH}$ at a certain ethanol to oil ratio irrespective of time has no glycerol in the product. Also for sodium hydroxide to react in totally different way than its other experiments could not get the gas chromatographic results, they could be helpful in determining the chemistry of the product under a number of experiments trials. The results best match with theoretical values and summarized in Table II. The values are within limits as revealed from research literature.

\section{REFERENCES}

[1] L. C. Meher, D. V. Sagar, and S. N. Naik, "Technical aspects of biodiesel production by transesterification- a review," Renewable and Sustainable Energy, vol. 10, issue 3, pp. 248-268, 2004.

[2] D. Leung, X. Wu, and M. Leung, "A review on biodiesel production using catalyzed transesterificatio," Energy the international journals, pp. 1-8, 2011.

[3] Demirbas, "A Progress and recent trends in biodiesel fuels," Energy Conversion and Management, vol. 50, issue 1, pp. 14-34, January. 2009. 
[4] J. M. Dias, M. C. M. Alvim-Ferraz, M. F. Almeida, "Comparison of the performance of different homogeneous alkali catalysts during transesterification of waste and virgin oils and evaluation of biodiesel quality," Fuel, vol. 87, issues. 17-18, pp. 3483-3718, December 2008.

[5] P. D. Patil and S. G. Deng, "Optimization of biodiesel production from edible and non-edible vegetable oils," Fuel, vol. 88, issue 7, pp. 1302-1306, July 2009, Elsevier Science.

[6] H. F. Liu, Y. Y. Liu, H. Zhou, Y. Yang, M. Y. Chen, and B. Liang, "Production of biodiesel from Jatropha curcas," Computers \& Chemical Engineering, vol. 33, issue 5, pp. 1091-1096., 21 May. 2009.

[7] N. U. Soriano Jr, R. Venditti, D. S. Argyropoulos, "Biodiesel synthesis via homogeneous Lewis acid-catalyzed transesterification," Fuel, vol. 88 , issue 3, pp. 560-565, 2009.

[8] J. M. Marchenetti, V. U. Miguel, and A. F. Errazu, "Possible methods for biodiesel production," Renewable and Sustainable Energy Reviews, vol. 11, issue 6, pp. 1300-1311, August 2007.
Muhammad Shahbaz is a chemical engineer and currently is working in University of Gujrat as lecturer. He has done his graduation in Chemical Engineering from Institute of Chemical Engineering and Technology, Punjab University, Lahore Pakistan in 2008. He did his master in Chemical Science Engineering with specialization in energy process from Royal Institute of Technology (KTH) Sweden in 2011. He worked on renewable fuels and submitted master thesis titled "Production of synthetic natural gas from gasification of biomass with integration of heat and power". He has accomplished many research projects related to bio gas, bio diesel and bio mass utilization. 